\title{
Breast reconstruction awareness among educated women in a metropolitan city
}

Sir,

In spite of the poor reporting system in India, it is very evident from the various statistics that the incidence of breast cancer is rapidly rising, amounting to a significant percentage of all cancers in women. ${ }^{[1]}$ Breast cancer is the commonest cancer in urban areas in India and its incidence in India is about $20.1 \%{ }^{[2]}$ According to a study by Dikshit et al., ${ }^{[3]}$ increasing trends in the incidence of breast cancer have been observed in India, including Mumbai. These have likely stemmed from an increasing adoption of lifestyle factors more akin to those commonly observed in westernized countries. Although the incidence of breast cancer is rising, breast reconstruction surgery for any purpose is very uncommon.

We conducted a survey with the purpose of knowing the awareness of reconstructive surgery. A simple questionnaire was prepared consisting of the following eight questions:

1. Are you aware of breast cancer?

2. Are you aware of treatment options for breast cancer?

3. If yes, what options do you know?

4. Are you aware of reconstructive surgery after operation of breast cancer?

5. If yes, what types of surgeries are you aware of?

6. Are you aware of aesthetic surgeries of the breast?

7. Do you know where are these surgeries performed and who does them?

The inclusion criteria were females, 20 years of age and above, who have completed basic education (minimum $10+2$ ). A total of 1000 participants were surveyed from various areas in Mumbai. The forms were segregated on the basis of age as follows: Category I, between 20 and 30 years $(n=374)$; category II, between 30 and 40 years $(n=290)$; category III, between 40 and 50 years $(n=208)$; and category IV, 50 years and above $(n=128)$.

Exactly 958 out of 1000 participants were aware of breast cancer, and out of these, only 653 were aware of 
the treatment options of breast cancer. A total of 336 participants were aware of surgery as an option, with maximum in category III (56\%) followed by I (53.3\%), II $(47.9 \%)$, and IV (46.6\%). Most of them were aware of chemotherapy $(87.1 \%$ in category I, $66.3 \%$ in II, $64 \%$ in III, and $56.8 \%$ in IV). Knowledge about radiotherapy was highest in category IV (38.6\%) which was close to the average of $31.9 \%$. A total of only 16 females knew about hormonal therapy out of which 11 (3.6\% of 336) were from category I.

Our main purpose was to know about the awareness of breast reconstruction. Only 242 of them were aware of reconstructive options after the treatment of carcinoma breast. The older group had a better knowledge about the options, as compared with the younger ones. Most of them said they had never heard about reconstruction after cancer surgery. Autologous reconstruction as a mode was known in category I, II, III, and IV by $51.1 \%$, $40.3 \%, 44.2 \%$, and $39.4 \%$ of the participants, respectively, out of 242 , which turns out to be $4.8 \%, 2.7 \%, 1.9 \%$, and $1.5 \%$ of the total number of participants in category I, II, III, and IV, respectively. Most of the females knew about implants (177, $17.7 \%$ of the total) and many of them came to know about them from newspapers and magazines. $9.9 \%$ of the total participants were aware of aesthetic surgeries of the breast (augmentation with implants). Most of them were of younger age group, that is, 76 out of 99 females were between 20 and 40 years. Also, 352 participants were aware of where these surgeries are being performed and only 127 females were aware of the names of various private hospitals in Mumbai. Most of the participants wrote the name of Tata Memorial Hospital (211). Only 14 of these participants were aware of such surgeries being performed in government hospitals.

No previous survey has been done in India regarding the awareness of breast cancer reconstruction surgeries. Although performed exclusively in Mumbai, this may reflect the level of awareness anywhere in India. Because being a metropolitan city, it has all the facilities of cancer detection, its treatment and reconstruction options are available in not only private hospitals, but also in all the government hospitals. Also, it has one of the highest numbers of plastic and reconstructive surgeons. In the USA, the women's Health and Cancer Rights Act was designed to ensure women's access to post-mastectomy breast reconstruction by mandating insurance coverage for these procedures. ${ }^{[4]}$ Still fewer than one-fifth of the women receive breast reconstruction at the time of mastectomy. ${ }^{[5]}$ In our survey, we only included women with basic education $(10+2)$, but to our surprise the results were very poor. The condition in rural areas is therefore hard to imagine.

Out of many reasons for low number of breast reconstruction, the main reason in India is lack of awareness of the cancer and its reconstructive options, which is evident from our survey. We believe that every woman undergoing treatment of breast cancer must be given the option for reconstruction and the operating surgeon has a big role to play in dispensing this awareness. In western countries, there are low rates of referral to plastic surgeons along with increasing use of reconstructive or oncoplastic surgery by general surgeons with an increasing trend in Europe for general surgeons to take over the entire surgical management of breast cancer patients. ${ }^{[6]}$ The government, NGOs, and other clinicians must understand that breast reconstruction is not a separate procedure, but a part and parcel of complete treatment of carcinoma breast, and therefore they should involve the plastic surgeons actively in the treatment.

If such is the condition amongst educated women, the task required to spread awareness within the rest of the women can be a real difficult task. Like epidemic diseases, all efforts should be made for spreading awareness amongst the entire population with various cancers, their detection, and possible treatment options.

"Reconstruction is not an option.... In fact, it is the right of the patient."

\section{Deepak S. Kothari, Amol N. Ghalme,} Sagar R. Gundewar

Department of Plastic Surgery, J. J. Hospital, Mumbai, Maharashtra, India

Address for correspondence: Dr. S. Deepak Kothari, Department of Plastic Surgery, Balaram Building, J. J. Hospital, Maharashtra, India. E-mail: drdeepak15@gmail.com

\section{REFERENCES}

1. An assessment of burden and care of cancer patients; Consolidated Report of Hospital Based Cancer Registries 204-2006; National Cancer Registry Programme, ICMR. Available from: http://icmr.nic.in/ncrp/cancer_reg.htm [Last cited on 15 the Feb 2012].

2. Burden of disease due to cancer in India. In: Park's Textbook of 
Social and Preventive Medicine, $20^{\text {th }}$ ed. Jabalpur: Banasidas Bhanot Publishers; 2009. p. 333.

3. Dikshit RP, Yeole BB, Nagrani R, Dhillon P, Badwe R, Bray F. Increase in breast cancer incidence among older women in Mumbai: 30-Year trends and predictions to 2025. Cancer Epidemiol 2012;36:e215-20.

4. Centers for Medicare and Medicaid Services. Available from: http://www.cms.gov/HealthInsReformforConsume/06_Th ewomen'sHealthandCancerRightsAct.asp. [Last cited on 10 Feb 2012].

5. Alderman AK, McMahon L Jr, Wilkins EG. The national utilization of immediate and early delayed breast reconstruction and the effect of sociodemographic factors. Plast Reconstr Surg 2003;111:695-703.

6. Quinn McGlothin TD. Breast surgery as a specialized practice. Am J Surg 2005;190:264-8.

\begin{tabular}{|l|l|}
\hline \multicolumn{2}{|c|}{ Access this article online } \\
\hline Quick Response Code: & Website: \\
\hline & www.ijps.org \\
\hline & Dol: \\
\hline & $10.4103 / 0970-0358.105985$ \\
\hline
\end{tabular}

